BULLETIN Bulletin hispanique

HISPANIQUE Université Michel de Montaigne Bordeaux

113-1 | 2011

Actes de 2 colloques

\title{
Poesía y géneros editoriales entre dos siglos
}

\section{Francisco J. Álvarez Amo}

\section{OpenEdition}

\section{Journals}

Edición electrónica

URL: http://journals.openedition.org/bulletinhispanique/1356

DOI: 10.4000/bulletinhispanique.1356

ISSN: $1775-3821$

\section{Editor}

Presses universitaires de Bordeaux

\section{Edición impresa}

Fecha de publicación: 1 junio 2011

Paginación: 313-329

ISBN: 978-2-86781-740-3

ISSN: 0007-4640

\section{Referencia electrónica}

Francisco J. Álvarez Amo, «Poesía y géneros editoriales entre dos siglos », Bulletin hispanique [En línea], 113-1 | 2011, Publicado el 01 junio 2014, consultado el 21 abril 2019. URL : http:/l journals.openedition.org/bulletinhispanique/1356 ; DOI : 10.4000/bulletinhispanique.1356 


\title{
Poesía y géneros editoriales entre dos siglos
}

\author{
Francisco J. Álvarez Amo \\ Universidad de Córdoba
}

La poésie imprimée à partir de 1650 présente des caractéristiques éditoriales relativement uniformes. Il convient d'en souligner deux principalement : la symbiose avec le marché du livre de petit format et l'abandon du modèle traditionnel de livre de poésie.

La poesía impresa a partir de 1650 presenta características editoriales bastante uniformes, de las que creo que conviene subrayar, sobre todo, dos: la simbiosis con el mercado del libro breve, de un lado; $y$, de otro, la difuminación del modelo previo de libro de poemas.

After 1650, the printing of poetry reveals quite homogeneous editorial features, two of which should be specially underscored, namely: its symbiotic relationship with the chapbook market, and its tendency towards the undoing of the traditional model of poetry book.

Mots-clés: Livre de poésie - Imprimerie - Marché du livre - Pliego - Amateurisme.

T os autores del siglo XVIII constituyen la culminación, o cuanto menos lírico en torno del libro impreso. Se ha repetido hasta la saciedad que los grandes versificadores del Quinientos estaban escasamente interesados en la difusión impresa de sus escritos. En las postrimerías del siglo XVI, sin

Bulletin Hispanique, Tome 113, nº 1 - juin 2011 - p. 313 à 329. 
embargo, la situación atraviesa momentos de cambio. El clímax coincide cronológicamente con la peripecia poético-biográfica de Fernando de Herrera y, en el año 1582, da lugar a la feliz impresión contemporánea de cuatro distintos libros de poemas en las mismas oficinas hispalenses de Andrea Pescioni ${ }^{1}$. Cabe fechar en este año y sus alrededores el comienzo de la definitiva consolidación del mercado del libro impreso en lo que a la poesía lírica se refiere. El libro de poemas deja de ser, a partir de entonces, el petrarquista "legado» del poeta, construido minuciosamente a lo largo de su vida y por lo común confiado a las prensas sólo de manera póstuma. Las equivalencias entre libro y vida se quiebran definitivamente: se huye no sólo del biografismo, sino hasta de la propia ficción biográfica² ${ }^{2}$.

El prestigio del poeta, a finales del siglo XVI y comienzos del XVII, depende de su presencia recurrente entre las novedades de los libreros. Y en el Setecientos, el ritmo de, digamos, un Lope, es insuficiente. La presión del mercado del libro impreso es tal que los poetas carecen incluso del tiempo necesario para confeccionar los ordinarios libros de poemas en cuarto. La solución es clara: integrarse en el más lucrativo o menos arriesgado mercado del folleto, del libro breve o, incluso, del pliego. Los libreros y el público, en efecto, no pueden o no quieren esperar los dos, tres años que separan las sucesivas ediciones de, siguiendo con el mismo ejemplo, los versos de Lope, e incesantemente requieren originales de los autores consagrados, sí, pero también de ese sinnúmero de aficionados que, a partir de ahora, accede sin obstáculos a las prensas.

Las circunstancias sociales y educativas del siglo XVIII promueven ciertamente que los poetas aficionados abandonen poco a poco el manuscrito en favor del libro de extensión breve. En el Setecientos aumenta el índice de alfabetismo de la población, así como el número y tamaño de las bibliotecas particulares. Se publican, entre 1703 y 1759, tres nuevas ediciones, quinta, sexta y séptima, del Rengifo, el vademécum del versificador, con adiciones que, según ha indicado Rafael de Cózar, afectan sobre todo a lo que tiene que ver con la composición de los artefactos poéticos más ingeniosos y complejos: acrósticos, retrógrados, laberintos, etc. ${ }^{3} \mathrm{Su}$ repercusión en la

1. J. Valentín Núñez Rivera, «1582 (Poesía, imprenta y canon)», en Begoña López Bueno (dir.), El canon poético en el siglo XVI, Sevilla, Universidad de Sevilla, 2008, pp. 141-175.

2. Francisco J. Álvarez Amo, “Iter ad caelum”: amor y poética en Herrera», en Pedro Ruiz Pérez (ed.), Cánones críticos en la poesía de los Siglos de Oro, Vigo, Academia del Hispanismo, 2008, pp. 171-180.

3. Rafael de Cózar, Poesía e imagen. Formas difíciles de ingenio literario, Sevilla, El Carro de la Nieve, 1993, pp. 344ss. Sobre el reinado del artificio en el bajo barroco, véase también Irving A. Leonard, Baroque Times in Old Mexico, Ann Arbor, The University of Michigan 
primera mitad del siglo excede, de lejos, a la casi despreciable de Luzán ${ }^{4}$. La precocidad de poetas y poetisas se subraya y publicita constantemente en las portadas de los impresos y en los epígrafes de las composiciones, lo que testifica en favor del lugar eminente de la poesía en la educación contemporánea. Parece que la formación de los aristócratas, en particular, adquiere cada vez mayor importancia, a medida que su integración en la burocracia del Estado se consolida, gracias en parte a instituciones como el Seminario de Nobles de Madrid 5 . Da la impresión, en efecto, de que la cifra de individuos capaces de escribir sonetos se multiplica en las postrimerías del siglo XVII y albores del siglo XVIII, y ello, a la par que la boga de antiguas y modernas prácticas sociales asociadas a la poesía, explica en gran medida el auge de las composiciones circunstanciales, plaga característica de la época. Recuérdese: «Más de la mitad de la producción literaria de sor Juana está compuesta por piezas de ocasión» (Octavio Paz, cit. n. 3, p. 249).

Me atrevería a escribir que el público del siglo XVIII era mucho más sofisticado, mucho menos plebeyo, de lo que se le ha reconocido hasta el momento. La sola mención de la palabra "pliego", cierto, suscita en nuestra imaginación el sintagma «de cordel»; en las líneas que siguen, no obstante, me propongo disolver el automatismo de esta asociación. Y es que el pliego, entendido en sentido amplio, ha sido en la España moderna vehículo de transmisión de la poesía lírica culta casi en igualdad de condiciones con el manuscrito y, después, con el libro propiamente dicho. A comienzos del siglo XVI, Juan de Mena, Manrique y el resto de poetas de cancionero se editaban continuamente en pliego. En el Seiscientos, las fábulas mitológicas fluyen en ocasiones sobre el mismo cauce (García de Enterría, cit. n. 19, pp. 384ss.). En el siglo siguiente, por fin, la pujanza del pliego suelto de poesía culta alcanza, como veremos, su cénit. Y es que, según ha escrito Jean-Marc Buigues, «de diez obras nuevas que se publican en el siglo XVIII, cuatro son opúsculos de menos de 50 páginas» ${ }^{6}$. Los autores contemporáneos advirtieron también

Press, 1959, pp. 155ss; y Octavio Paz, Sor Juana Inés de la Cruz o Las trampas de la fe, México, F.C.E., 2008, p. 83.

4. Joaquín Arce, La poesía del siglo ilustrado, Madrid, Alhambra, 1981, pp. 144-145, con la n. 2, y p. 188, con la n. 1. Autores más o menos clasicistas como Garcilaso o Luis de León no parecen tampoco haber gozado del favor de los poetas de comienzos del siglo XVIII; véanse, ibid., pp. 117, con la n. 1, y 125.

5. Véase el elogio entusiasta de Diego de Torres Villarroel, en Visiones y visitas con don Francisco de Quevedo, ed. de Rusell P. Sebold, Madrid, Espasa, 1991, pp. 288ss.

6. Víctor Infantes, François Lopez y Jean-François Botrel (dirs.), Historia de la edición y la lectura en España, Madrid, Fundación Germán Sánchez Ruipérez, 2003, p. 298. La cita de Cadalso que viene a continuación procede de Cartas marruecas. Noches lúgubres, ed. de Emilio Martínez Mata, Barcelona, Crítica, 2000, p. 222; la de Jovellanos, de El delincuente honrado, 
el éxito del libro de extensión breve y pequeño formato. Baste con remitir a Cadalso ("iNo te espanta la suerte de tanto libro en folio, que yace entre el polvo de las librerías, ni te estimula la fortuna de tanto libro pequeño, que se reimprime millares de veces, sin bastar su número a tanto tocador y chimenea que toma por desaire el verse sin ellos?») y a Jovellanos («Hombre hubo que sobre una ley de dos renglones escribió un tomo en folio. Pero hoy se piensa de otro modo. Todo se reduce a libritos en octavo»).

En el Setecientos, así, es frecuente que composiciones exentas visiten asiduamente las prensas mucho antes de integrarse en antologías y compilaciones de autor. Diego de Torres Villarroel alude explícitamente a esta construcción progresiva del libro en el "Cuarto trozo» de su autobiografía, donde se lee: «[e]scribía también [...] los papelillos que hoy se van cosiendo en tomos grandes» ${ }^{7}$. En las secciones publicitarias de la prensa periódica contemporánea, estos pequeños libritos reciben a menudo el nombre de «papeles», en tanto que sus hermanos mayores se denominan, por supuesto, «libros». La distinción semántica «libros y papeles» aparece también en Cadalso (cit. n. 6, p. 188) y en la autobiografía de Diego de Torres Villarroel (cit. n. 7, pp. 222, 259): según es sabido, Villarroel se ganaba la vida con almanaques, pronósticos y parecidos géneros de extensión reducida, a los que se refiere, de ordinario, con expresiones como "papeles» o "papelillos» (cit. n. 7, pp. 118, 165, 226, 349 et passim). Cuando efectivamente existe, el libro de versos líricos se convierte, como demuestra a la perfección el caso de Eugenio Gerardo Lobo ${ }^{8}$, en poemario in fieri que exige sucesivas ediciones en que se van integrando los versos inéditos, aunque no necesariamente nuevos, del autor. Hay también poetas que, incapaces de ir añadiendo composiciones adicionales en improbables reediciones de sus obras, evitan dar a las prensas la edición autorizada de su poesía, que finalmente acaba publicándose póstuma o, en el mejor de los casos, coincidiendo con los últimos años de vida del poeta en cuestión.

Don Francisco Benegasi y Luján y su hijo José Joaquín ejemplifican la modificación de las actitudes de los escritores, en el siglo XVIII, respecto del mercado del libro. Las obras de don Francisco se divulgaron manuscritas, según a su nobleza convenía. José Joaquín, sin embargo, tuvo a bien recoger

ed. de Rusell P. Sebold, Madrid, Cátedra, 2008, p. 117.

7. Diego de Torres Villarroel, Vida, ascendencia, nacimiento, crianza y aventuras, edición de María Angulo Egea, Barcelona, DeBolsillo, 2005, p. 165. En el «Trozo quinto», p. 270, se refiere de nuevo a esta costumbre: «Reiréme siempre que vea a mis descuadernados disparates subidos a ser tomos en las mejores librerías de España».

8. Francisco J. Álvarez Amo, «Peripecias editoriales de Eugenio Gerardo Lobo», en Ignacio García Aguilar, cit. n. 9, pp. 199-215. 
las que pudo con el objetivo de darlas a las prensas adicionadas con las suyas propias. Lo hizo, según parece, en dos ocasiones muy cercanas en el tiempo: 1744 y 1746. El libro de 1746 es reedición ampliadísima del de 1744, que contenía, exclusivamente, obras dramáticas; en él, los textos del hijo duplican a los del padre, lo que viene a significar que José Joaquín Benegasi blandía la excusa de la recuperación de los escritos de su progenitor como pretexto para la edición de los suyos propios. En la portada misma de 1746 se avisa, en efecto, de que el volumen contiene composiciones de José Joaquín Benegasi "posteriores a su primer tomo lírico», de 1743 , y, por tanto, inéditas; van señaladas, como en el caso de los versos de Lobo, edición de 1738, por medio de la correspondiente marca tipográfica. Benegasi volvería a la carga en 1752, año en que se vuelven a imprimir sus obras poéticas con el añadido, oportunamente publicitado en portada, de su narración en redondillas de la vida de San Dámaso, de la que de momento no conozco ediciones previas, pero que, sin embargo, se volvió a publicar exenta posteriormente. La propia portada, de paso, comunica a los lectores que los tres libros de poemas anteriores $(1743,1744,1746)$ siguen a la venta en la Librería del Mercurio. Tengo noticia de otra edición de las obras de José Joaquín Benegasi, sin fecha pero de h. 1754, salida de la oficina madrileña de Miguel Escribano: su portada, orgullosa, anuncia que contiene nada menos que el doble de composiciones que las ediciones previas, ampliamente publicitadas también en el cuadernillo de preliminares. Las adiciones van precedidas, por supuesto, del inevitable asterisco. Me gustaría citar algunas palabras procedentes de la «Nota» liminar, que confirman en parte lo que llevo dicho sobre el carácter heteróclito del libro de poesía en los albores del siglo XVIII; escribe Benegasi que: «el Tomo se compone de una micelania [...] como succede en las más Obras Lýricas; y en todas ellas (o en la mayor parte) se observa en su colocación no el mejor orden». La heterogénea estructura de los libros de poesía de su tiempo se debe, según el propio autor, a que «los más Letores se precian de tan delicados paladares que fundan todo su gusto en la variedad, y quieren assí las Obras porque assí las quieren».

Si el caso de José Joaquín Benegasi y Luján es, como sus similitudes con la trayectoria poética de Eugenio Gerardo Lobo parecen sugerir, representativo, hay que concluir que los poetas del siglo XVIII se movían como pez en el agua dentro del mercado del libro impreso. Baste con traer a la memoria los casos, en absoluto infrecuentes, de poetas que editan a otros poetas. Diego de Torres Villarroel, según ha estudiado Jaime Galbarro, saca a luz en 1744 los versos de Gabriel Álvarez de Toledo?. José Joaquín Benegasi,

9. Jaime Galbarro García, «Gabriel Álvarez de Toledo y la dispositio textus de las Obras 
como hemos visto, edita las obras de su progenitor, entremetiendo de paso las suyas propias; también se convierte, en 1754, en editor póstumo del carmelita fray Juan de la Concepción. Se dice, en fin, que el propio Lobo contemplaba la posibilidad de supervisar la impresión de los versos de José Antonio Porcel y Salablanca ${ }^{10}$.

Permítaseme de todas formas subrayar el hecho de que, también en el siglo XVIII, hay autores que eligen deliberadamente mantenerse al margen de la estampa. Su elección, igual que posturas similares en el Siglo de Oro estricto, tiene mucho de toma de partido sociológico-estética. Los que optan por la transmisión manuscrita de sus obras son, sobre todo, autores en órbita más bien gongorino-culterana, como Alonso de Verdugo, conde de Torrepalma, o el propio José Antonio Porcel, miembros ambos de la granadina Academia del Trípode que, con el tiempo, acabaron engrosando las filas de la Ilustración.

Como hemos comprobado en los casos de Eugenio Gerardo Lobo y José Joaquín Benegasi y Luján, en el Seiscientos se difumina el concepto de libro de poemas de autor. Existen además, en la poesía del barroco tardío, otras constantes que adquieren rango de tendencia o movimiento a partir de, aproximadamente, la segunda mitad del siglo XVII. Tal vez haya que vincular el inicio del propio bajo barroco con la poesía de Francisco de Quevedo o, mejor dicho, con la impresión de las obras poéticas de Francisco de Quevedo, que, de acuerdo con la opinión de, entre otros, Manuel Ángel Candelas, comienzan a ejercer su influencia, precisamente, gracias a los dos picos de popularidad que les proporcionan las sucesivas aunque espaciadas ediciones de González de Salas y Pedro de Aldrete ${ }^{11}$. Conviene profundizar, ciertamente, en algunas de las lecturas favoritas de los aficionados a la poesía de comienzos del Setecientos. Quevedo se convierte, según decía, en el autor más influyente del período, llegando a producir casos tan acentuados de usurpación de estilo y casi de personalidad como el que representa Diego de Torres Villarroel. Éste, llevado del desengaño, se deshizo de su biblioteca antes de cumplir los treinta y cuatro años; solamente quiso conservar varios libros religiosos y, por supuesto, alguno de don Francisco (cit. n. 7, pp. 8182). Las obras poéticas de autores que mueren en la segunda mitad del siglo XVII, por otra parte, se editan con cierta frecuencia, o cuando menos se

pósthumas poéticas (Madrid, 1744)», en Ignacio García Aguilar (ed.), Tras el canon. La poesía del Barroco tardio. Vigo: Academia del Hispanismo, 2009, pp. 217-229.

10. José María Escribano Escribano, Biografía y obra de Eugenio Gerardo Lobo, Toledo, Diputación Provincial de Toledo, 1996, p. 73.

11. Manuel Ángel Candelas Colodrón, «El modelo de Quevedo», en Ignacio García Aguilar (ed.), cit. n. 9, pp. 25-39. 
reeditan, en la primera mitad del siglo XVIII. A Antonio Enríquez Gómez se le imprime, de nuevo, en los albores mismos del Setecientos. Las obras poéticas de Manuel de León Marchante, muerto desde 1680, no vieron la luz, en tres volúmenes, hasta el siglo XVIII ${ }^{12}$. La edición príncipe de las obras poéticas de Antonio de Solís y Ribadeneyra, muerto desde 1686, data de 1692, pero conoce dos reimpresiones en la primera mitad del siglo siguiente $^{13}$. Las de José Pérez de Montoro se editaron en 1736, divididas en dos volúmenes. Y las de sor Juana, muerta en 1695, se vendieron a espuertas en el primer cuarto del siglo XVIII ${ }^{14}$. Son Francisco de Quevedo y estos en ocasiones casi desconocidos poetas de la segunda mitad del Seiscientos, más que los autores del Siglo de Oro estricto, quienes marcan la pauta en la mitad oscura del Siglo de las Luces.

La poesía impresa a partir de 1650 presenta, por lo demás, características editoriales bastante uniformes, de las que creo que conviene subrayar, sobre todo, dos: la simbiosis con el mercado del libro breve, de un lado; y, de otro, la difuminación del modelo previo de libro de poemas. Sobre este último aspecto ha llamado la atención, recientemente, Ignacio García Aguilar, quien subraya sobre todo la inclusión, cada vez más y más común a partir de la segunda mitad del siglo XVII, de composiciones originadas en acontecimientos sociales de diverso tipo, particularmente academias, dentro del libro de poesía ${ }^{15}$. Me preocupa más, de todos modos, la cuestión de las nuevas vías de acceso a la imprenta. En el Setecientos asistimos, según anteriormente sostenía, a cierta simbiosis entre el libro de poemas en cuarto y los folletos o pequeños volúmenes. Es preciso, sin embargo, recurrir a la sinopsis histórica para comprender el alcance del fenómeno. Con propósitos ilustrativos, voy a servirme de la figura paradigmática de Eugenio Gerardo Lobo, el prolífico poeta de la primera mitad del siglo XVIII. Sus composiciones circulaban exentas, en pliego o pequeño volumen, mucho antes de que ninguno de sus libros de poemas viese la luz. Y sucede, de hecho, que las primeras ediciones de sus obras poéticas carecen por completo de organicidad. Se limitan a ser colecciones de impresiones sueltas. Es

12. Martha Lilio Tenorio, «Sor Juana y León Marchante», Nueva Revista de Filología Hispánica, no 50.2, 2002, p. 543, n. 3 .

13. Pedro Ruiz Pérez, «Edición y canon: la publicación póstuma de Antonio de Solís (1692)", Jornadas de Estudios Románicos, Bratislava, AnaPress, 2008, pp. 257-269.

14. Octavio Paz, cit. n. 3, pp. 363-364; Françoise Étienvre, «Fortuna editorial de la poesía del siglo XVII en la primera mitad del siglo XVIII", en Ignacio García Aguilar, cit. n. 9, pp. 183-198.

15. Ignacio García Aguilar, «Tras el Parnaso (1648): aproximación a modelos editoriales de mediados del XVII», en Ignacio García Aguilar, cit. n. 9, pp. 61-76. 
infrecuente en ellas que aparezca en la misma página el final de algún poema y el comienzo de otro. Lo común es que el inicio de cada texto coincida con el de la página. Si sobra espacio en el desenlace, se colma gracias a los más diversos artificios tipográficos. En multitud de ocasiones, el formato de los epígrafes sugiere, de hecho, portadas independientes. Baste con remitir a la portadilla que precede a las octavas del «Sitio, ataque y rendición de Lérida» en la edición gaditana de 1717, p. 95. Desde el punto de vista del investigador, además, Eugenio Gerardo Lobo presenta la indiscutible ventaja de que se refiere explícitamente a la integración de sus propias composiciones en el mercado del pliego. En este sentido, es interesante la cita que trae Julio Caro Baroja (cit. n. 18, pp. 82-83, n. 99), extraída de las décimas «yo, aquel capitán Gerardo", que aparecen ya recogidas en la antes mencionada edición gaditana de 1717. En ellas, Eugenio Gerardo Lobo alude a que algunos de sus borradores, extraviados, acabaron en manos de los impresores, de las que pasaron, sin solución de continuidad, a las de los $\operatorname{ciegos}^{16}$.

$\mathrm{Y}$ es que la poesía culta del siglo XVIII, aunque mantiene siempre su identidad tipográfica, acaba contaminándose, a veces, de algunas de las características de las composiciones que se difundían a través de este popularísimo vehículo de transmisión. El formato, en efecto, dista de ser simple cuestión de forma y acaba, en ocasiones, condicionando el propio contenido. La poesía culta del bajo barroco corría el riesgo de contagiarse poco a poco de las características de la poesía vulgar de los pliegos de cordel: de ahí el nuevo reinado del octosílabo, en romances anodinos de extensión inverosímil; de ahí el predominio de lo chabacano-religioso; de ahí el "prosaísmo» y, sobre todo, el famoso «aplebeyamiento» de la poesía culta, otro de los sub-productos de la adopción del «majismo" como pauta de conducta entre las clases aristocráticas del Setecientos (Sarrailh, cit. n. 29, p. 519). Cobra sentido profundo, en el contexto de estas reflexiones, que Eugenio Gerardo Lobo recibiese el sobrenombre de "capitán coplero» (véase, por ejemplo, Joaquín Arce, cit. n. 4, p. 149), o que Diego de Torres Villarroel se designe a sí mismo «versificante de antuvión, coplero tolerado sin cargos de conciencia» ${ }^{17}$. Y es que, según con acierto subraya Pedro Ruiz Pérez, en el siglo XVIII se confirman los resquemores de los autores más o menos intelectualizantes del Siglo de Oro estricto, «quienes entrevieron que la vulgarización era la cruz inevitable de los procesos de divulgación» ${ }^{18}$.

16. En este punto, conviene citar a M. Ángeles García Collado, Los libros de cordel en el Siglo Ilustrado, Tesis Doctoral de la Universidad del País Vasco, Vitoria, 1997, que no he visto todavía.

17. La cita de Diego de Torres Villarroel procede del vol. VII de sus obras (Salamanca, Antonio José Villagordo y Alcaraz, 1752), p. 7. 
En el Setecientos asistimos, de hecho, a la gestación y nacimiento de nuevas modas editoriales cuya matriz fue, ordinariamente, el pliego. Algo habría que decir sobre las "relaciones de comedias»" ${ }^{19}$, a veces también injeridas dentro del libro de poesía lírica; prefiero detenerme, sin embargo, en la boga dieciochesca del folleto o libro pequeño. Y es que, según ha escrito Inmaculada Osuna ${ }^{20}$,

ni el poemario de autor único ni la antología pensada desde un criterio selectivo más o menos variado en cronología y autoría [...] constituyeron los formatos editoriales únicos, y ni siquiera los más frecuentes, para reflejar y difundir la abundancia poética de la época.

La edición de antologías y de libros de poemas en el Setecientos es, en comparación, más bien reducida y me arriesgaría incluso a decir que poco representativa del patrón mayoritario de trayectoria poética. En cuanto a los poetas del siglo XVIII, son conocidas las peripecias editoriales de Eugenio Gerardo Lobo, José Joaquín Benegasi y Luján y muchos otros. Ahora bien: como en el caso de Granada, que Inmaculada Osuna analiza, hay innumerables autores en el conjunto de Espańa que prefieren acceder a las prensas a través del libro de pequeño volumen, que suele editarse en cuarto y constar, como academias y justas, de entre tres y ocho decenas de páginas (Inmaculada Osuna, ibid., p. 81, n. 4), siendo lo más frecuente que se sitúe en torno de la media centena.

El libro breve se especializa, en principio, en la transmisión de la épica militar y sagrada, géneros ambos que se beneficiaban del hecho de haber sido publicados exentos desde antiguo, de haber, en definitiva, consolidado su relación biunívoca con el objeto «libro» desde la llegada misma del ingenio de Gutenberg a tierras iberas. Citemos, por caso, la Conquista del reino de

18. Pedro Ruiz Pérez, «Modelos editoriales y perfiles de autor tras el canon áureo (16501750)», en Ignacio García Aguilar, cit. n. 9, pp. 109-124. La cita, en la p. 124. Sobre este punto véase también, a propósito de Lobo, Julio Caro Baroja, Ensayo sobre la literatura de cordel, Madrid, Istmo, 1990, p. 26.

19. Julio Caro Baroja, cit. n. 18, pp. 219ss.; María Cruz García de Enterría, Sociedad y poesia de cordel en el Barroco, Madrid, Taurus, 1973, pp. 336ss.; Jaime Moll, «Un tomo facticio de pliegos sueltos y el origen de las "Relaciones de comedias"”, en Jaime Moll, De la imprenta al lector, Madrid, Arco Libros, pp. 57-75; Víctor Infantes, François López y Jean-François Botrel, cit. n. 6, p. 409. García de Enterría propone adelantar la boga de las relaciones de comedia hasta finales del siglo XVII, aunque muchos de los pliegos sobre los que apoya su argumentación carecen de fecha.

20. Inmaculada Osuna, «Poesía post-barroca y tipología editorial: producción y carreras literarias en Granada en la segunda mitad del siglo XVII», en Ignacio García Aguilar, cit. n. 9, pp. 77-107. La cita, en la p. 77. 
Nápoles, de Diego de Torres Villarroel, en octavas, con distintas impresiones sin fecha que cabe datar h. 1735 (véase Joaquín Arce, cit. n. 4, p. 152, n. 13). El libro épico breve se distingue de la epopeya propiamente dicha: su menor extensión justifica, por ejemplo, la adopción de peculiares sobrenombres. Alcanzó cierta popularidad el de "rasgo», en el doble sentido de «bosquejo sin perfilar y no acabado" y de "acción noble y digna de alabanza", que he localizado en varios impresos del lapso 1700-1750 y en multitud de anuncios aparecidos en la sección publicitaria de la Gazeta de Madrid. El más célebre de ellos se debe precisamente a Eugenio Gerardo Lobo. Su Rasgo épico de la conquista de Orán, del que Aguilar Piñal cita tres ediciones de 1732 (Madrid, Zaragoza, Barcelona) y otras dos sin fecha (Sevilla, Córdoba), vio la luz exento. Poco después de que las impresiones sueltas comenzasen a difundirse, pero todavía dentro de 1732, entró a formar parte de la segunda impresión barcelonesa de sus obras poéticas completas ${ }^{21}$.

Seis años más tarde, en dos romances de 1732 añadidos a la edición de 1738, Lobo da cuenta de su regreso de Orán y proporciona algunas valiosas confidencias sobre su incursión última en el ámbito de la epopeya. Me interesa sobre todo el segundo de ellos, "Estas de mi ronca tuba», que lleva el siguiente epígrafe: «Remitiendo a su especial y erudito amigo don Juan de la Cueva una copia de las octavas del Rasgo épico de la conquista de Orán, principiadas en la misma expedición, proseguidas en el navío y finalizadas en Barcelona». El autor, después de zigzaguear a propósito de la imitación de los clásicos, informa de que hay quienes critican la llaneza de sus versos y reconoce que raras veces vuelve sobre lo escrito para efectuar correcciones. Su descripción corresponde, siempre, a la del escritor aficionado que versifica en sus ratos de ocio. Pero Lobo, a la vez, quiere que sus versos se impriman; eso, cuando menos, se desprende de los cuatro versos con que concluye la composición: "Quédate en paz y procura / que en la patria se publique, / para memoria, ese rasgo, / de los triunfos de Felipe». Y, efectivamente, la epopeya se dio a las prensas, aunque curiosamente sin el nombre del autor, ¡a pesar de que este había urgido personalmente su impresión y de que el folleto, de hecho, proporciona la pista de sus iniciales ("D.E.G.L.»)!: otro ejemplo del ordinario toma y daca entre los modos tradicionales del escritor aficionado y las modernas servidumbres del mercado del libro impreso.

La simbiosis entre libro pequeño y género épico contamina también impresos que, sin pertenecer exactamente a la epopeya, se acercan a su estilo sublime. Y el hecho de que la Soledad tercera, de José León y Mansilla, o La augusta Belisa, de José Joaquín Benegasi, se publicasen como folletos o libros pequeños, en mi opinión, lo demuestra.

21. Sobre esta pieza, véase Joaquín Arce, cit. n. 4, pp. 158ss. 
Poco he dicho acerca de las epopeyas sagradas aparecidas en forma de libro-poema. El siglo XVIII, en su primera mitad, fue más bien pacato, y ello dio lugar a la impresión de docenas y docenas de sueltas de carácter chabacano-religioso. Emilio Palacios Fernández trae a colación muchas de ellas ${ }^{22}$; subraya, como aquí se ha hecho antes, el modo en que varios de los poetas barroquizantes más prestigiados del siglo XVIII adoptaron, además del soporte, los temas y tonos característicos del pliego popular. De entre los perpetradores de epopeyas sagradas en pequeño formato me gustaría citar, en lugar preferente, a Gabriel de León y Luna. En 1734 vio la luz su Sacra y bumana lyra, en las prensas madrileńas de Juan Muńoz. Parece que Gabriel de León, a quien se describe en los preliminares como modesto, humilde y recogido, quiso delegar en su amigo Juan Manuel de Palacio la publicación de sus versos; llama la atención, sin embargo, que el propio Gabriel de León fuese, después de todo, el titular del privilegio. El volumen se abre con el "Viaje y destierro de Nuestra Señora a Egypto», que antes, en 1722, se había impreso en el soporte característico del libro-poema propiamente dicho, es decir: en alrededor del medio centenar de páginas en cuarto. La inclusión del «Viaje y destierro de Nuestra Señora a Egypto» vuelve a demostrar que el libro de poemas se estaba convirtiendo, progresivamente, en inorgánico libro de aluvión donde se recogían composiciones exentas que habían visitado las prensas anteriormente $y$, a modo de complemento, algunos versos inéditos que los autores, en muchas ocasiones, habían presentado a diversos certámenes y que sin mayor problema acababan facilitando a los impresores. Era frecuente, como acreditan las obras de Sor Juana Inés de la Cruz (Octavio Paz, cit. n. 3, p. 395), Gabriel de León, Eugenio Gerardo Lobo y algún otro contemporáneo, incluir en los libros de poemas cartas privadas escritas en verso octosílabo y, por supuesto, textos circunstanciales surgidos de las más diversas situaciones de la vida cortesana. Se trata de poemas que a menudo son incomprensibles si se desconoce la ocasión concreta que dio origen a su escritura, de la que los epígrafes se ven obligados a dar extensísima cuenta, provocando que algunos de ellos se extiendan, como ocurre en el libro de poemas de Gabriel de León, a lo largo de líneas y líneas, ocupando, casi y sin el «casi», páginas completas. En las obras de Gabriel de León no existe, de hecho, ninguna composición que se sustraiga a este carácter circunstancial; es evidente que Gabriel de León era, meramente, un aficionado, aunque, según argumento más adelante, en sentido distinto del que solemos adjudicar a esta denominación.

22. «Evolución de la poesía en el siglo XVIII», < http://www.cervantesvirtual.com/servlet / SirveObras/01361697588915403423802/p0000001.htm>. 
La boga del libro pequeño dio lugar a la emergencia de nuevos centros de impresión y, en consecuencia, a cierta reorganización del mercado editorial; según escribe Jean-Marc Buigues, «son veintidós las ciudades que no tenían actividad editorial a principios de siglo y que en la década de los ochenta la tienen» (cit. n. 6, p. 304). Los tradicionales libros de poemas seguían siendo, por defecto, el cauce de difusión de la poesía lírica. La pujanza de los «papeles» o pliegos de poesía culta, sin embargo, era cada vez más perceptible. Los modestos empresarios de provincias, que a duras penas se arriesgaban a editar libros propiamente dichos, se podían permitir, en cambio, apostar por la edición de poesía en forma de libro pequeño o de pliego. El ordinario lugar de edición de los volúmenes de poesía lírica sigue siendo, por supuesto, Madrid o algún núcleo de similares características, y las excepciones se pueden explicar en virtud de las circunstancias personales de los autores en cuestión. Diego de Torres Villarroel, salmantino, imprime los catorce tomos de sus obras completas en Salamanca, ciudad en que, además, ostentaba cierta autoridad intelectual, a veces discutida, en virtud de su condición de profesor universitario. Las ediciones de Eugenio Gerardo Lobo, a su vez, calcan a la perfección el periplo biográfico del itinerante capitán coplero. Pero lo cierto es que, en este momento, cualquier oscuro librero de provincias puede dar a las prensas pliegos y pequeños libros sin asumir excesivos costes ni riesgos. Así, surgen nuevos centros impresores en ciudades que no habían sido, desde este punto de vista, especialmente relevantes en siglos anteriores. Aunque Julio Caro Baroja se mueve, por la mayor parte, en fechas más tardías de las que nos interesan aquí, quiero citar como ejemplo su aseveración de que "Córdoba ha sido [...] un foco de producción de pliegos de cordel de importancia digna de ser subrayada» ${ }^{23}$. Julio Caro Baroja se refiere, sobre todo, a impresores que, como Luis de Ramos y Coria, Fausto García Tena o Rafael García Rodríguez, viven y trabajan mayormente en el siglo XIX; disponemos, sin embargo, de noticias adicionales sobre la producción cordobesa de libros pequeños, no necesariamente literarios, a lo largo del Setecientos: el maestro François Lopez llega a escribir que, en esta época, Córdoba aparece «en la lista de los diez primeros centros tipográficos de España» (cit. n. 6, p. 342). La moda de las relaciones de comedias, nacidas, según Jaime Moll, en Sevilla, se acaba trasladando, sobre todo a partir de 1725, a la vecina Ciudad de los Omeyas (cit. n. 19, p. 59, n. 8). Las actividades de Antonio Ximénez, mercero, muestran también las posibilidades comerciales que el mercado del libro de

23. Julio Caro Baroja, cit. n. 18, p. 90; véase también María Cruz García de Enterría, cit. n. 19, pp. 67-71. 
pequeño volumen suscitaba: Antonio Ximénez distribuía entre los libreros de Córdoba las cartillas que, en virtud de privilegio regio, producía en exclusiva el Prior y Cabildo de la Iglesia Colegial de la villa de Valladolid ${ }^{24}$.

$\mathrm{El}$ auge de los centros provincianos de impresión deriva también de la eclosión, a partir de la segunda mitad del siglo XVII, de formas de socialización literaria que, aunque, por supuesto, existían previamente, alcanzan ahora grados de publicidad antes desconocidos. Baste con recordar que las actas de sesiones académicas no comienzan a visitar las prensas, de hecho, hasta la segunda mitad del Seiscientos ${ }^{25}$. Su despacho lejos del lugar de celebración de las sesiones en cuestión carece casi absolutamente de sentido. La impresión debe realizarse, en consecuencia, en oficinas de provincias que la edición de «academias» contribuye grandemente a vitalizar. Hojeando el imprescindible catálogo descriptivo de Alain Bègue se advierte que, aunque los grandes centros editoriales como Madrid o Sevilla monopolizan la impresión de «academias» en la segunda mitad del siglo XVII, pequeñas localidades como Ciudad Real o Badajoz se sitúan también, poco a poco, en el mapa de la estampa española ${ }^{26}$.

Muchos de los poetas que contribuyen con sus composiciones a las "academias» impresas pertenecen, claramente, a la categoría de los versificadores aficionados que practican la escritura, exclusivamente, en el contexto de circunstancias sociales propicias a la exhibición del ingenio; antes, sin embargo, de evaluar su grado de "amateurismo», conviene subrayar, con propósitos ilustrativos, cómo la evolución y características de la poesía española de este período coinciden con las de otros países europeos y, sobre todo, con las de Inglaterra.

Parece, en efecto, que la literatura isabelina estuvo sometida a circunstancias sociales, económicas e ideológicas asimilables, cuando menos en parte, a las españolas ${ }^{27}$. Así, en las postrimerías del siglo XVI y comienzos del siglo

24. Jaime Moll, «La "cartilla” y su distribución en el siglo XVIII», en Jaime Moll, cit. n. 19, pp. 77-87 y esp. pp. 85-86.

25. Francisco J. Álvarez, Ignacio García Aguilar e Inmaculada Osuna, «Seventeenth-century Academies in the City of Granada: a Comparatist Approach», en Arjan van Dixhoorn y Susie Speakman Sutch (eds.), The Reach of the Republic of Letters, Leiden, Brill, 2008, pp. 309-336, esp. p. 318.

26. Alain Bègue, Las academias literarias en la segunda mitad del siglo XVII, Madrid, Biblioteca Nacional, 2007.

27. Las reflexiones que figuran a continuación derivan de la lectura de Richard Helgerson, Self-Crowned Laureautes. Spenser, Jonson, Milton, and the Literary Sistem, Berkeley, University of California Press, 1983. El autor, fallecido en 2008, se ocupó de Garcilaso en su último libro, A Sonnet from Carthage. Garcilaso de la Vega and the New Poetry of Seventeenth-Century Europe, Philadelphia, University of Pennsylvania Press, 2007. 
XVII, se registra, como en Espańa, el declinar de los asuntos amorosos a que generalmente nosotros aludimos con la fórmula «superación del petrarquismo» y que Richard Helgerson atribuye, en el caso de Inglaterra, a la influencia ejemplarizante de la trayectoria poética de Edmund Spenser. John Milton y sus contemporáneos del Seiscientos tardío son, por su parte, preciosistas: igual que los escritores españoles tardobarrocos, vivieron a la sombra de los grandes poetas de las generaciones anteriores, se consagraron a la escritura de composiciones de ocasión e hicieron del estilo, más que del contenido, su marca distintiva.

Richard Helgerson aísla tres patrones de trayectoria poética en el período que, en sentido amplio, vamos a denominar sencillamente isabelino, a pesar de que se prolonga hasta los reinados de Jacobo I y Carlos I; sería instructivo, creo, comprobar la aplicabilidad de su fórmula en el caso de los escritores españoles del Siglo de Oro. Los auto-proclamados poetas del título del ensayo de Helgerson no se avergüenzan de su cultivo de la poesía: se muestran, de hecho, fervientes partidarios de la transmisión impresa de sus textos y abandonan progresivamente la neoplatónica doctrina del furor poético en favor de concepciones más profesionales de la creación, vinculadas a los conceptos de esfuerzo, dedicación y similares. En el caso de Jonson, ejemplar desde este punto de vista, baste con remitir a su elogio de Shakespeare en los preliminares del First Folio, donde asegura que "[w] ho casts to write a living line, must sweat» y que "a good poet», en definitiva, "[i]s made as well as born» ${ }^{28}$.

Los poetas profesionales como Cristopher Marlowe o William Shakespeare, a su vez, tienen bien clara su función: ganarse la vida a cambio de complacer a su público. El género a que se dedicaron casi exclusivamente fue, por supuesto, el drama. En el bajo barroco castellano, creo que el caso más evidente de escritor profesional es el de Diego de Torres Villarroel. Hijo de librero, su actitud hacia el mercado de la letra impresa carecía por completo de romanticismo. En el «Primer trozo» de su autobiografía confiesa: «Yo soy autor de doce libros, y todos los he escrito con el ansia de ganar dinero para mantenerme» (cit. n. 7, p. 80). Y se mantenía, precisamente, gracias a sus repetidas incursiones en el ámbito del libro breve, del almanaque, del pronóstico; despreciaba, o afectaba despreciar, el resto de su producción

28. Las palabras entrecomilladas proceden de James Shapiro, A Year in the Life of William Shakespeare: 1599, New York, HarperCollins, 2005, p. 320. Sobre este relevante aspecto del pensamiento de Jonson, véase muy especialmente Richard Helgerson, cit. n. 27, pp. 119ss. Sobre la penetración en España de similares concepciones de la creación poética, véase, por ejemplo, Pedro Ruiz Pérez, La distinción cervantina. Poética e historia, Alcalá de Henares, Centro de Estudios Cervantinos, 2006, p. 48. 
y, en particular, sus obras específicamente poéticas (p. 208). Llevaba la cuenta exacta de los prólogos («ochenta y cinco» hacia 1750, p. 209) y dedicatorias ("cientoveinte» hacia 1743, p. 119) que había escrito y, por supuesto, del dinero que sus impresos le habían reportado: «En veinte años de escritor he percibido a más de dos mil ducados cada año» (p. 118) ${ }^{29}$. Llegó a denunciar personalmente ante las autoridades a los responsables de dos ediciones hurtadas de su autobiografía, que, lógicamente, acabaron en sus manos después de la acostumbrada confiscación (pp. 215-216). Sus obras completas de 1752 se pusieron a la venta a través del procedimiento, entonces novedoso en España, de la suscripción (p. 276). La autobiografía de Diego de Torres Villarroel ofrece, por lo demás, curiosas ventanas a la vida cotidiana del escritor en el siglo XVIII temprano. Es impagable, por ejemplo, el episodio en que, en misa, el sacerdote lee la consabida lista de autores y títulos prohibidos y el piadoso Diego de Torres, de pronto, oye pronunciar su propio nombre (pp. 222ss.). La personalidad de Diego de Torres Villarroel era, en fin, abiertamente burguesa. A diferencia de Shakespeare o Lope, que con mayor o menor fundamento forjaron escudos de armas con que convencer a sus contemporáneos de la nobleza sociológica de sus antepasados, Diego de Torres Villarroel publicita, en los primeros compases de su autobiografía, el origen más bien villano de su familia. Los verdaderos intelectuales del siglo XVIII, entre los que cuento, aunque quizás no debiera, a sus compañeros en el claustro salmantino, le hacían el vacío, pero Diego de Torres, con palabras a veces proféticas, presume sin cesar de haber triunfado sobre ellos: «muchas centurias después de difunto, he de ser citado por hombre insigne y, como quien no dice nada, por autor de libros" (p. 269).

Helgerson se refiere también, y esto es lo que ahora me interesa particularmente subrayar, a los poetas aficionados o amateurs que, como John Donne, cultivan la poesía de forma diletante y reproducen en sus biografías la parábola del hijo pródigo: emplean sus años de juventud en la composición de poemas y reniegan de ellos en la edad provecta ${ }^{30}$. Los puntos de vista de Helgerson sobre el concepto de «amateurismo», que Javier Jiménez Belmonte ha aplicado, en tiempos recientes, a Francisco de Borja, príncipe de Esquilache, se pueden completar con algunas reflexiones coincidentes de Roger Chartier $^{31}$. El escritor amateur, según Chartier,

29. Cfr. con Jean Sarrailh, La España ilustrada en la segunda mitad del siglo XVIII, México, F.C.E., 1957 , pp. 60-61.

30. Sobre ellos trata, en exclusiva, The Elizabethan Prodigals, Berkeley, University of California Press, 1977.

31. Javier Jiménez Belmonte, Las obras en verso del principe de Esquilache, Londres, Tamesis, 
vive no de su pluma, sino de sus bienes o de su empleo; desprecia lo impreso, expresando su «antipatía respecto de un medio de comunicación que pervertía los antiguos valores de intimidad y de escasez de ejemplares ligados a la literatura de la corte». Prefiere el público elegido entre sus pares, la circulación en forma de manuscrito y el ocultamiento del nombre propio detrás del anonimato de la obra.

Parece claro que, en el bajo barroco, gran parte de la producción poética ocurre bajo el signo del "amateurismo»; sucede, sin embargo, que los poetas aficionados de comienzos del Setecientos mantienen, respecto del mercado del libro impreso, actitudes divergentes de las de sus homólogos en el Siglo de Oro estricto. La trayectoria ordinaria de estos nuevos aficionados queda ejemplificada con los tres autores granadinos traídos a colación en los últimos párrafos del artículo de Inmaculada Osuna a que me he referido más arriba, en la n. 20; a pesar de no pertenecer, ni de lejos, a la categoría de los que Helgerson denomina «auto-proclamados» poetas, algunas de sus composiciones se publican, bien como pliegos sueltos, bien dentro de pequeños libros, personales o colectivos. Hay poetas aficionados, como Gabriel de León, que incluso llegan a ver impresas sus obras en la forma clásica del volumen de poesías líricas sin que semejante cambio de soporte implique, ni mucho menos, que los poetas en cuestión aspiren a trascender su propio «amateurismo». Llama la atención, de hecho, el elevado número de autores que, todavía en el siglo XVIII, se despreocupan absolutamente de vigilar, en persona, la impresión de sus versos, de la que se acaba encargando circunstancialmente algún editor espontáneo.

Sorprenden asimismo los peregrinos expedientes que algunos poetas eligen con el propósito de des-personalizar la edición de sus versos: sor Juana Inés de la Cruz, a pesar de haber intervenido personalmente en la preparación de varias de sus ediciones tempranas, atribuye la publicación de sus versos a personas que han actuado sin su consentimiento (Octavio Paz, cit. n. 3, p. 363); José Joaquín Benegasi Luján se auto-edita bajo el pretexto de publicar las obras de su padre; Eugenio Gerardo Lobo, a su vez, autoriza a la oscura Congregación de la Milagrosa Imagen de Nuestra Señora de Peńa Sacra para que, en su nombre, saque a luz la edición "definitiva» de sus obras (Francisco J. Álvarez Amo, cit. n. 2); algo parecido se puede predicar, también, de Gabriel de León y Luna, que deja que otro publique sus versos, aunque con el privilegio, por supuesto, a su nombre; Diego de

2007. La cita de Roger Chartier que aparece a continuación procede de El orden de los libros, Barcelona, Gedisa, 2000, p. 52. Las palabras entrecomilladas pertenecen a Alvin Kernan, Printing Technology, Letters and Samuel Johnson, Princeton, Princeton University Press, 1987. 
Torres Villarroel, por fin, atribuye la recopilación e impresión de sus obras líricas, de las que afecta desentenderse, a la iniciativa interesada de su famoso primo, el librero salmantino Antonio Villarroel y Torres.

Vemos, pues, cómo el triángulo poeta-público-mercado, en los primeros compases del siglo XVIII, altera dramáticamente la situación relativa de sus vértices, sin que, por otra parte, parezca razonable establecer secuencias indiscutibles de causas y efectos. ¿Hay que atribuir la boga del folleto o libro pequeño a lo económico de su producción, o tal vez a que los poetas se ven obligados a surtir regularmente de novedades las librerías? ¿Se debe la impresión de "academias», a partir de la segunda mitad del siglo XVII, a que las composiciones surgidas de ellas comienzan a invadir, poco a poco, el libro de poemas, o quizás invaden el libro de poemas, precisamente, porque han comenzado a editarse exentas? Carece de sentido pronunciarse en favor de cualesquiera de las mencionadas hipótesis; es la conjunción misma de circunstancias coadyuvantes la que conduce inevitablemente a este o aquel ulterior desarrollo histórico. Los poetas del Setecientos, como los del Siglo de Oro estricto, mantienen ciertamente vínculos problemáticos con el mercado del libro impreso; sucede, empero, que el rango de sus problemas es, en gran medida, diverso del de sus predecesores. El poeta del Setecientos ignora en contadísimas ocasiones la existencia de la difusión impresa del libro de poemas; hasta el más oscuro de los aficionados, según hemos visto, acababa, tarde o temprano, en la estampa. Esta ubicuidad de la imprenta, lógicamente, enfrenta a los poetas del siglo XVIII con patrones de comportamiento absolutamente extraordinarios en tiempo de sus antecesores y maestros en el oficio. Un estudio minucioso del modo en que los diferentes invididuospoetas del Setecientos se enfrentaron a este complejo entramado de opciones y posibilidades daría lugar, en mi opinión, a resultados fascinantes. 